\title{
BRUCELLA BACTERIOPHAGE
}

\author{
By M. J. PICKETT AND ERIC L. NELSON \\ From the Department of Bacteriology, University of California at \\ Los Angeles
}

Smith's recent (1949) attempts, with failure, to isolate bacteriophage active upon Brucella have prompted us to present a preliminary report on certain phenomena observed during the course of our work with these bacteria. We are interpreting these phenomena as being referable to the presence of Brucella bacteriophage although, thus far, we have been unable to obtain results comparable to those which would be found in a typical lytic system, for instance, in an active colibacteriophage system.

Our attention was first directed toward a consideration of Brucella bacteriophage when what appeared to be distinct plaques were seen in the confluent growth of a mucoid Brucella variant on an agar plate. This variant, in turn, had been recovered from the blood of a patient ill with chronic brucellosis. More recently, numerous phenomena associated both with blood cultures from normal and 'brucellar' humans and also with stock Brucella cultures have been observed which we feel can best be interpreted as referable to the presence of weakly lytic bacteriophage. Among these we may note: (1) Of two Brucella abortus, one Br. melitensis, and one Br. suis isolated from patients by the California State Board of Health and recently sent to us, all were found to be viable upon subculture to a solid medium but three of these showed confluent lysis after 3 days' incubation. (2) Of eight cultures received from the Los Angeles County General Hospital, all showed areas of lysis on plating to solid media. (3) Broth cultures of concentrated blood specimens frequently show a definite though slight and slowly developing turbidity which, however, does not yield growth upon subculturing to a solid medium. (4) Several of our stock mucoid Brucella cultures show almost complete lysis in broth and on solid medium after several days' incubation. (5) Addition of diluted filtrates, thought to contain Brucella bacteriophage, to young broth cultures of stock smooth $\mathrm{Br}$. abortus frequently do not prevent development of what appears to be uniform turbidity in the broth. Gram stains prepared from these, however, show much debris with few formed cells, and subcultures to a solid medium frequently fail to yield growth. (6) Finally, filtrates from mucoid lysogenic Brucella variants, when added to stock smooth $\mathrm{Br}$. abortus broth cultures will in turn give rise to mucoid, and frequently lysogenic, variants.

\section{MATERIALS AND METHODS}

The basal culture medium (CTN) was constituted as follows:

$\begin{array}{lclc} & \% & & \% \\ \text { Albimi C peptone } & 2 \cdot 0 & \text { Thiamine hydrochloride } & 0.0001 \\ \text { Sodium chloride } & 0.5 & \text { Nicotinamide } & 0.0001 \\ \text { Glucose } & 0.2 & & \end{array}$


The peptone, a pancreatic digest of casein, was obtained from the Albimi Laboratories, Brooklyn, New York. The basal medium, as such, was tubed in suitable amounts for broth media; $2 \%$ of washed $(25 \mathrm{~g}$. agar on a Büchner funnel was treated with 11. distilled water, drained, and dried in vacuo over sulphuric acid) Difco agar was added for plating media; and $2 \mathrm{ml}$. amounts of basal medium containing $1 \%$ of washed Difco agar were used in the 'agar-layer' method (Hershey, Kalmanson \& Bronfenbrenner, 1943) for bacteriophage titrations. All cultures were incubated at $35^{\circ} \mathrm{C}$. under elevated carbon dioxide tension unless otherwise indicated.

A smooth, virulent, strain of $B r$. abortus (no. $3 d 2$ ), obtained from Dr C. M. Carpenter, was used throughout most of the work here reported, although we are now examining several other strains of $\mathrm{Br}$. abortus in respect to bacteriophage sensitivity.

Two filtrates were examined for Brucella bacteriophage activity. The first, F-1, was derived from a pool of potentially lysogenic Brucella variants obtained from blood cultures (Pickett \& Nelson, 1950). The pool was prepared by collecting saline suspensions and broth cultures of these variants. About $10 \mathrm{ml}$. of this pool was then centrifuged and the supernatant fluid was added to $100 \mathrm{ml}$. of a $12 \mathrm{hr}$. $B r$. abortus (no. $3 d 2$ ) broth culture. This mixture was incubated another $48 \mathrm{hr}$., an aliquot was centrifuged and this supernatant fluid was enriched a second time by passage through a broth culture of $3 d 2$. Plating from this enrichment showed evidence of lysis and a few isolated plaques. A few of the lysed colonies were added, along with supernatant fluid from the second enrichment culture, to a third and final enrichment culture in $3 d 2$. The final culture was centrifuged, the supernatant fluid was filtered through a Corning UF filter, and the filtrate was stored at $4^{\circ} \mathrm{C}$. A second filtrate, F-2, prepared in a manner similar to that described above, and for which $3 d 2$ was again the enriching culture, was obtained from a pool of a culturally unstable smooth $B r$. abortus (no. $4 a$, received from the New England Deaconess Hospital, Boston, Mass.) and several mucoid variants derived from it.

The two filtrates were titrated for bacteriophage by first preparing decimal dilutions of these in $2 \mathrm{ml}$. of CTN broth. Each dilution tube then received $0.05 \mathrm{ml}$. of Brucella no. $3 d 2$ suspension, the latter having been obtained by suspending a $48 \mathrm{hr}$. CTN agar slant culture in $4 \mathrm{ml}$. of CTN broth. The Brucella-filtrate mixtures were then incubated $15 \mathrm{~min}$. at room temperature, $0.4 \mathrm{ml}$. of the mixture was added to $2 \mathrm{ml}$. of melted, $45^{\circ} \mathrm{C}$., CTN $1 \%$ agar, and this was layered over a Petri plate of CTN $2 \%$ agar. These plates, along with the heavily inoculated dilution tubes, were incubated $48 \mathrm{hr}$. before being examined for the presence of plaques or other evidence of bacteriophage activity. In addition, the dilution tubes, which always showed abundant turbidity after this $48 \mathrm{hr}$. incubation period, were usually subcultured on fourth or sixth sectors of CTN plates. In a few instances the agar-layer procedure just described was altered to the extent that $0 \cdot 1 \mathrm{ml}$. from each filtrate dilution tube, then $0.1 \mathrm{ml}$. of Brucella suspension, were added in turn to a tube of melted agar and this was immediately layered over a plate of CTN agar. This latter method appeared, however, to give somewhat less consistent 
results and less distinct plaques than were obtained by the method first described.

The data obtained from these titrations (Table 1) indicate that each filtrate contained a lytic principle at significant titre. It is also apparent that in every instance a distinct and broad 'prozone' was obtained, presumably due to a blocking effect in the presence of excess bacteriophage. Nevertheless, it would appear from the results presented in Table 2 that the lower dilution tubes also contained infected Brucella, since subcultures from these tubes to sectors of plates usually failed to yield growth of smooth Brucella.

Table 1. 'Agar-layer' titration of Brucella bacteriophage

Dilution of filtrate

$\begin{array}{lllllllllll}\begin{array}{l}\text { Con- } \\ \text { trol }\end{array} 10^{-1} & 10^{-2} & 10^{-3} & 10^{-4} & 10^{-5} & 10^{-6} & 10^{-7} & 10^{-8} & 10^{-9} & 10^{-10}\end{array}$

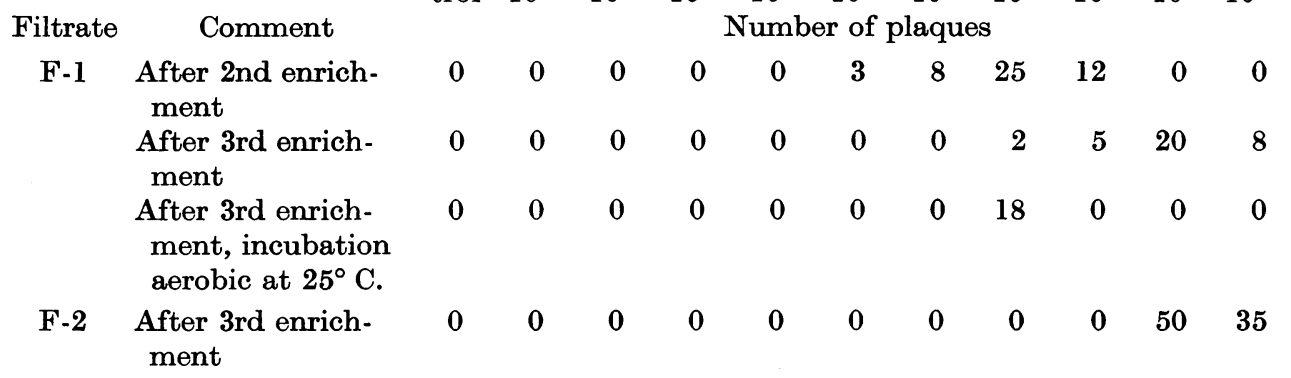

Table 2. Results obtained upon sector-platings from filtrate dilution tubes, showing relative amount of growth (control $=100)$ and approximate percentage of this which was culturally smooth, and number of plaques on this growth

Dilution tube

\begin{tabular}{clrrrrrrrrrrr} 
Filtrate & \multicolumn{1}{c}{ Growth } & trol & $10^{-0}$ & $10^{-1}$ & $10^{-2}$ & $10^{-3}$ & $10^{-4}$ & $10^{-5}$ & $10^{-6}$ & $10^{-7}$ & $10^{-8}$ & $10^{-9}$ \\
F-1 & Relative amount & 100 & 5 & 25 & 65 & 60 & 10 & 45 & 45 & 45 & 60 & 15 \\
& Approx. \% smooth & 100 & 0 & 0 & 5 & 15 & 100 & 30 & 30 & 30 & 25 & 30 \\
& Number plaques & 0 & 3 & 6 & 0 & 0 & 0 & 4 & 0 & 0 & 50 & 0 \\
F-2 & Relative amount & 100 & 60 & 0 & 20 & 30 & 40 & 40 & 30 & 25 & 5 & 15 \\
& $\%$ smooth & 0 & 45 & 0 & 0 & 0 & 0 & 0 & 0 & 0 & 0 & 0 \\
& Number plaques & 0 & 30 & 0 & & \multicolumn{7}{c}{ Confluent partial lysis } \\
& & & & & & & &
\end{tabular}

On several occasions, though as yet not reproducible, the 'prozone' plates bore many mucoid Brucella variants, usually the 'mucoid-pink' or 'smooth-brown' variants described by Pickett \& Nelson (1950). In most instances the plaques obtained on these plates were of uniform size, approximately $0.4 \mathrm{~mm}$. in diameter, and were found upon examination under a dissecting microscope to contain microcolonies. We are, however, currently examining human blood plasma filtrates which give rise not only to small plaques but also to plaques of $1.5 \mathrm{~mm}$. diameter. Fishings from the centres of the larger plaques, when transferred to broth cultures of susceptible $3 d 2$ Brucella, lead to demonstrable infection of the latter. 


\section{DISCUSSION}

The data reported here, along with other as yet unpublished studies, have led us to conclude that we can be dealing only with Brucella bacteriophage. This appears to be neither a strongly lytic nor an easily demonstrable bacteriophage, however. On the contrary, we are now of the opinion that, unless special experimental conditions be established for this system, the rate of multiplication of the Brucella will exceed that of the bacteriophage, and that frank lysis will rarely be manifest. Nevertheless, we have come to recognize the following phenomena during the course of our studies and suspect that all are referable to bacteriophage activity: (1) the development of what appear to be autolytic and sometimes lysogenic non-smooth Brucella variants from known smooth cultures; (2) a greatly prolonged lag period when broth is lightly inoculated with infected smooth Brucella; (3) inability to obtain growth upon plating from 3-7-day, heavily turbid, broth cultures of initially smooth Brucella; and (4) the atypical microscopic morphology of infected Brucella.

These characteristics of our Brucella cultures do not, of course, constitute unequivocal proof that bacteriophage is present, but the evidence does strongly favour this interpretation, and similar phenomena have been observed in other bacteriophage systems (see Delbrück, 1942). Furthermore, our obtaining of plaques repeatedly within the same range of filtrate dilutions and our occasional obtaining of transient but definite clearing of broth cultures are unquestionably phenomena associated with bacteriophage activity.

\section{SUMMARY}

Filtrates prepared from suspensions and broth cultures of Brucella variants were examined for the presence of Brucella bacteriophage. Smooth Brucella, when mixed with decimal dilutions of these filtrates in broth, (1) contained typical bacteriophage plaques when inoculated on solid medium, and (2) gave a heavy turbidity in broth after suitable incubation, but frequently failed to yield visible growth upon plating from these broth cultures to a solid medium. These data were discussed in terms of Brucella bacteriophage, and it is concluded that the presence of this virus best accounted for the phenomena observed.

\section{REFERENCES}

Delbrück, M. (1942). Bacterial viruses (bacteriophages). Advanc. Enzymol. $2,1$.

Hershey, A. D., Kalmanson, G. \& Bronfenbrenner, J. (1943). Quantitative methods in the study of the phage-antiphage reaction. J. Immunol. 46, 267.

Picketr, M. J. \& Nelson, E. L. (1950). Incidence of Brucella in 'normal' human bloods. Society of American Bacteriologists, Bacteriological Proceedings, 42.

Sмгтн, H. W. (1949). A search for bacteriophages active upon bacteria of the Brucella genus. J. Hyg., Camb., 47, 414. 